\title{
Miniaturized Membrane Sensors for the Determination of Orphenadrine Citrate
}

\author{
Marianne Nebsen ${ }^{1, *}$, Mohamed K. Abd El-Rahman ${ }^{1}$, Amira M. El-Kosasy ${ }^{2}$, \\ Maissa Y. Salem ${ }^{1}$, Mohamed G. El-Bardicy ${ }^{1}$ \\ ${ }^{1}$ Analytical Chemistry Department, Faculty of Pharmacy, Cairo University, Kasr-El Aini \\ street, 11562 Cairo, Egypt \\ ${ }^{2}$ Pharmaceutical Analytical Chemistry Department, Faculty of Pharmacy, Ain Shams \\ University, Cairo, Egypt
}

Received 24 November 2010; accepted 10 June 2011

\begin{abstract}
Novel miniaturized polyvinyl chloride (PVC) membrane sensors in all-solid state graphite and platinum wire supports were developed, electrochemically evaluated and used for the assay of orphenadrine citrate (ORP). The ORP sensors were based on the formation of an ion-association complex between the drug cation and tetrakis(4chlorophenyl)borate (TpCIPB) anionic exchanger as electroactive material dispersed in a PVC matrix. Linear responses of $10^{-2}-10^{-5} \mathrm{M}$ and $10^{-2}-10^{-4} \mathrm{M}$ with cationic slopes of $56.4 \mathrm{mV}$ and $53.6 \mathrm{mV}$ over the $\mathrm{pH}$ range 4-7 were obtained by using the ORP-coated graphite (sensor 1) and platinum wire (sensor 2) membrane sensors, respectively. The proposed methods displayed useful analytical characteristics for the determination of ORP in Norflex ${ }^{\circledR}$ tablets with average recoveries of $100.01 \pm 0.83,100.09 \pm 0.90$, and in plasma with average recoveries of $99.4 \pm 0.97$ and $98.55 \pm 0.82$, for sensor 1 and 2 , respectively. The methods were also used to determine the intact drug in the presence of its degradate and thus could be used as stability indicating methods. The results obtained by the proposed procedures were statistically analyzed and compared with those obtained by using an official method. No significant difference for both accuracy and precision was observed.
\end{abstract}

Keywords: orphenadrine citrate, potentiometry, stability indicating method, tetrakis(4chlorophenyl) borate, plasma.

\footnotetext{
* Corresponding author. E-mail address: mariannenebsen@ hotmail.com
} 


\section{Introduction}

Orphenadrine citrate [(RS)-(dimethyl-2-(2-methylbenzhydroxy)ethyl) amine citrate $\left(\mathrm{C}_{18} \mathrm{H}_{23} \mathrm{NO}, \mathrm{C}_{6} \mathrm{H}_{8} \mathrm{O}_{7}\right.$, mol. wt. 461.5$\left.)\right]$ is most widely employed as skeletal muscle relaxant [1] It acts centrally by depressing the appropriate neurons to prevent the generation of somatic molar nerve impulses. Several methods have been applied in the literature for the determination of ORP in dosage forms and in biological fluids. Techniques such as spectrophotometry [2-6], potentiometry [7], gas chromatography-mass spectrometry (GC-MS) [8-10], atomic absorption $[3,10]$ and high performance liquid chromatography (HPLC) [11-13], have been used.

From all these procedures only the HPLC technique [13] was recommended as a stability indicating assay. The potentiometric method reported for determination of ORP by ion selective electrode [7], used ammonium reineckate as anionic exchanger and nitrobenzene as plasticizer. This electrode, however, wasn't examined with ORP major degradation product o-methylbenzhydrol, and drugs co-formulated with ORP, such as paracetamol, caffeine and aspirin, and their selectivity coefficients were tested for only a few organic and inorganic cations. Tetrakis(4-chlorophenyl)borate (TpClPB) was reported as famous ion exchanger [14-16]. It was used in the formation of many sensors [17-19]. In this work, it was found that ORP reacted with (TpClPB) to form water insoluble ion association complex. The high lipophilicity and remarkable stability of this complex suggested its selective use as electroactive material in PVC matrix membrane sensors for the determination of the drug studied, in the presence of its degradate and related substances.[20]

The aim of this work was to develop simple sensors of low cost with fast response to be applicable in turbid, viscous and coloured solutions. These sensors offered highly sensitive and selective technique for the determination of ORP as a pure drug, in pharmaceutical dosage forms and in the presence of ORP degradation product and co-formulated drugs.

\section{Experimental}

Instruments

A Jenway digital ion analyzer model 3330 (Essex, UK) with a $\mathrm{Ag} / \mathrm{AgCl}$ double junction reference electrode no. 924017-LO-Q11C was used for potential measurements.

Bandelin sonorox magnetic stirrer model Rx $510 \mathrm{~S}$, (Budapest, Hungary) was used during measurements.

A Jenway pH glass electrode No. 924005-BO3-Q11C (Essex, UK) was used for $\mathrm{pH}$ adjustments.

\section{Chemicals and reagents}

Orphenadrine citrate reference standard was kindly supplied by Egyptian International Pharmaceutical Industrial Company "EIPICO", (Cairo, Egypt), its purity was certified to be $99.43 \%$. $o$-methylbenzhydrol (degradation product of ORP) was obtained from Sigma chemical company (St. Louis, MO). Its purity 
was labelled to be $98.69 \%$. Norflex ${ }^{\circledR}$ tablets (labelled to contain $100 \mathrm{mg}$ orphenadrine citrate per tablet), were obtained from Egyptian International Pharmaceutical Industrial Company "EIPICO”, (Cairo, Egypt).

All chemicals and reagents used were of analytical reagent grade. Water used was bi-distilled. Polyvinyl chloride (PVC) high molecular weight, dioctyl phthalate (DOP) and tetrakis (4-chlorophenyl) borate (TpClPB) were purchased from Aldrich (Steinheim, Germany). Tetrahydrofuran (THF) BDH (Poole, England). Hydrochloric acid Prolabo (PA, USA). Britton-Robinson buffer (BRB) ( $\mathrm{pH}$ 2-12) was prepared by mixing different volumes of $0.04 \mathrm{M}$ acetic acid, 0.04 $\mathrm{M}$ phosphoric acid, $0.04 \mathrm{M}$ boric acid and $0.2 \mathrm{M}$ sodium hydroxide [21]. Fresh human plasma was supplied by (VACSERA, Giza, Egypt) and used within 24 hours.

\section{Standard solutions}

- ORP stock standard solution $\left(1 \times 10^{-2} \mathrm{M}\right)$ :

Prepared by transferring $0.461 \mathrm{~g}$ of ORP into $100 \mathrm{~mL}$ volumetric flask and completing the volume with bi-distilled water using BRB solution to adjust $\mathrm{pH}$ at 6.

- ORP working solutions $\left(1 \times 10^{-6}-1 \times 10^{-2} \mathrm{M}\right)$ :

Prepared by suitable dilution from ORP stock standard solution.

- ORP degradate ( $o$-methylbenzhydrol) standard solution $\left(1 \times 10^{-3} \mathrm{M}\right)$ :

Prepared by transferring $0.199 \mathrm{~g}$ of $o$-methylbenzhydrol into $100-\mathrm{mL}$ volumetric flask and completing the volume with bi-distilled water using BRB solution to adjust $\mathrm{pH}$ at 6.

\section{Procedures}

Preparation of electroactive coating membrane: (ORP/TpClPB /PVC)

Five $\mathrm{mL} 10^{-2} \mathrm{M}$ aqueous drug solution were acidified with two drops of $1 \mathrm{M}$ hydrochloric acid and mixed with the saturated aqueous solution of TpCIPB. The resultant precipitate was filtered, washed with cold water, dried at room temperature (about $20{ }^{\circ} \mathrm{C}$ ) and grounded to fine powder, forming the ion-pair complex. Elemental analysis was carried out to study the formation of the complex.

In a glass Petri dish ( $5 \mathrm{~cm}$ diameter), $10 \mathrm{mg}$ of the previously prepared ion association complex were mixed thoroughly with $0.35 \mathrm{~mL}$ DOP and $0.19 \mathrm{~g}$ PVC. The mixture was dissolved in $5 \mathrm{~mL}$ THF, and then the Petri dish was covered with a filter paper and left to stand for one hour to allow slow evaporation of the solvent, producing a thick homogeneous master coating PVC solution.

\section{Sensor 1 fabrication (ORP-coated graphite electrode)}

A rod of spectrographic graphite (6 $\mathrm{mm}$ in diameter and $15 \mathrm{~mm}$ long) was inserted in a polyethylene sleeve, and about $3 \mathrm{~mm}$ of the other end of the protruded rod served as a measuring surface. This end of the rod was washed with acetone, dried in air for three hours, and dipped rapidly into the previously prepared PVC solution. The solvent was allowed to evaporate in air after each dipping, and the dipping process was repeated 6-8 times to produce a uniform 
membrane on the surface of the graphite rod. One drop of mercury was added in the polyethylene sleeve to ensure electrical contact with the connection cable. The coated graphite rod was conditioned by soaking in a $10^{-2} \mathrm{M}$ ORP solution for five hours, and stored in the same solution when not in use.

\section{Sensor 2 fabrication (ORP-coated platinum wire electrode)}

The cover of an insulated platinum wire ( $2 \mathrm{~mm}$ in diameter and $10 \mathrm{~mm}$ in length) was removed for a length of about $1 \mathrm{~cm}$ at both ends. One end of the wire was immersed in the previously prepared PVC solution and was left to stand for 10 min to allow complete air drying, forming a thin membrane around the wire end. The resultant coated wire membrane sensor was conditioned in $10^{-2} \mathrm{M}$ drug solution for three hours and was stored in the same solution when not in use.

\section{Sensors calibration}

The conditioned sensors were calibrated by separately transferring $50 \mathrm{~mL}$ aliquots of solutions $\left(1 \times 10^{-6}-1 \times 10^{-2} \mathrm{M}\right)$ of ORP into a series of $100-\mathrm{mL}$ beakers. The membrane sensors in conjunction with $\mathrm{Ag} / \mathrm{AgCl}$ reference electrode were immersed in the above test solutions and allowed to equilibrate while stirring. The potential was recorded after stabilizing to $\pm 1 \mathrm{mV}$ and the emf was plotted as a function of negative logarithm of ORP concentration. The calibration plots obtained were used for subsequent measurements of unknown samples of ORP.

\section{Application to pharmaceutical formulations (Norflex ${ }^{\circledR}$ tablets)}

The contents of 10 tablets were weighed, grounded and mixed thoroughly. A suitable portion of powder equivalent to $0.0461 \mathrm{~g}$ ORP was transferred into a 100 $\mathrm{mL}$ volumetric flask; then $50 \mathrm{~mL}$ of bi-distilled water were added. The solution was shaken for 3 minutes before completing to the mark with the same solvent and using BRB solution to adjust $\mathrm{pH}$ to 6 . This prepared solution is a $10^{-3} \mathrm{M}$ aqueous solution of ORP. Suitable dilutions were performed to obtain serial of $10^{-4}$ to $10^{-5} \mathrm{M}$ ORP using bi-distilled water and adjusting the $\mathrm{pH}$ to 6 by BRB solution. The procedure was completed as described under sensors calibration.

Application to synthetic mixtures containing different amounts of ORP degradate Aliquots of standard drug solution $\left(10^{-3} \mathrm{M}\right)$ were mixed with ORP degradate standard solution $\left(10^{-3} \mathrm{M}\right)$ in different ratios. The emf of $50 \mathrm{~mL}$ portions of these laboratory prepared mixtures was recorded. Results were computed according to the corresponding regression equation.

\section{Application to plasma}

$1 \mathrm{~mL}$ of $10^{-2}, 10^{-3}$ and $10^{-4} \mathrm{M}$ standard drug solution were added separately into three stoppered shaking tubes $(20 \mathrm{~mL})$, each containing $9 \mathrm{~mL}$ of plasma which was previously adjusted to $\mathrm{pH} 6$ with BRB solution. The tubes were shaken for 1 minute. The membrane sensors were immersed in conjunction with the reference electrode in these solutions, and then washed with water between measurements. The emf produced for each solution was measured by the proposed electrodes; 
then the concentration of ORP was determined from the corresponding regression equation.

\section{Results and discussion}

Microelectrodes are the subject of much research in recent years and the advantages they offer over conventional electrodes are well known [22,23]. Metallic and graphite-based conductors of many geometric shapes have been suggested, such as wire, disc and cylinders [24, 25]. These electrodes behave as two interface devices, membrane/electrolyte interface and membrane/metal interface [26]. Coated wire electrodes (CWEs) for some cations and anions [28] were described [27-29]. Also coated graphite rods were used as sensors for the determination of some drugs such as atenolol [30], tizanidine [31] and rivastigmine [32].

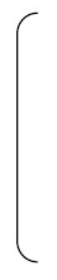<smiles>Cc1ccccc1C(OCCN(C)C)c1ccccc1</smiles>

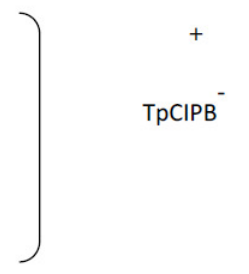

Figure 1. Suggested structural formula of ion association complex of ORP with TpCIB.

ORP contains a tertiary amino group and behaves as cation in acidic media - as $\mathrm{HCl}$ was added during preparation of electroactive coating membrane - the fact that suggests the use of anionic type of ion exchangers to form complexes with it. TpCIPB with its low solubility product and suitable grain size was found to be optimum for the formation of 1:1 hydrophobic ion association complex with the studied drug, Fig. 1. The complex ratio between TpCIPB and the drug was 1:1 as proved by elemental analysis, Table 1.

Table 1. Elemental analysis of ORP-TpCIPB complex.

\begin{tabular}{|c|c|c|c|}
\hline \multirow{2}{*}{ Parameters } & \multicolumn{3}{|c|}{ Onalysis \% } \\
\cline { 2 - 4 } & \multicolumn{3}{|c|}{ ORP-TpClPB } \\
\cline { 2 - 4 } & $\mathrm{C}$ & $\mathrm{H}$ & $\mathrm{N}$ \\
\hline Calculated \%* & 74.13 & 7.83 & 6.31 \\
\hline Found \% & 73.72 & 7.06 & 6.91 \\
\hline
\end{tabular}

\section{Sensors fabrication}

A microsized graphite and platinum wire coated with thin films of PVC-ORPTpClPB were prepared and used as potentiometric sensors for ORP drug. Upon soaking these sensors in $10^{-2} \mathrm{M}$ drug solution, a homogenous electroactive polymer-ORP site was formed, which induced a potentiometric response for the ORP cation through an ion-exchange mechanism. 
It has been reported that PVC acts as a regular support matrix for the membrane and reproducible trap for the ions sensed [33-35], but its use created a need for a mediator [36]. In the present investigation, DOP (a non polar plasticizer) was found to be the optimum available mediator for the PVC membrane sensors. It plasticized the membrane, dissolved the ion association complexes and adjusted both of the membrane permittivity and ion exchanger sites mobility to give the highest possible selectivity and sensitivity. Except for dibutylsebacate which had the same effect as DOP, other mediators such as, tricresylphosphate and castor oil failed in dissolving the ion association complexes and thus gave noisy responses. The membrane constituents were dissolved in THF that was slowly evaporated at room temperature, leading to the formation of thick homogeneous PVC-ORP-TpCIPB solution for coating of both the graphite rod and platinum wire.

Table 2. Electrochemical response characteristics of the two investigated ORP electrodes.

\begin{tabular}{|c|c|c|}
\hline Parameter & ORP-coated graphite & $\begin{array}{l}\text { ORP-coated } \\
\text { platinum wire }\end{array}$ \\
\hline Slope $(\mathrm{mV} / \text { decade })^{\mathrm{a}}$ & 54.8 & 51.6 \\
\hline Intercept $(\mathrm{mV})$ & 316.3 & 65.1 \\
\hline $\operatorname{LOD}(\mathrm{M})^{\mathrm{b}}$ & $6.8 \times 10^{-6}$ & $5.8 \times 10^{-5}$ \\
\hline Response time (sec.) & 5 & 7 \\
\hline Working $\mathrm{pH}$ range & $4-7$ & $4-7$ \\
\hline Concentration range $(\mathrm{M})$ & $10^{-5}-10^{-2}$ & $10^{-4}-10^{-2}$ \\
\hline Stability (days) & 42 & 18 \\
\hline Average recovery $(\%) \pm$ S.D. $^{a}$ & $99.97 \pm 0.66$ & $99.94 \pm 0.76$ \\
\hline Correlation coefficient & 0.9999 & 0.9998 \\
\hline Ruggedness $^{\mathrm{c}}$ & 99.67 & 99.35 \\
\hline \multicolumn{3}{|c|}{$\begin{array}{l}\text { a Average of five determinations } \\
\mathbf{b} \text { Limit of detection (measured by interception of the extrapolated arms of Fig. } 2 \text { and } 3 \text {. } \\
\text { c Average recovery percent of determining } 10^{-3}, 10^{-4} \text { M ORP for the studied electrodes using a } \\
\text { Jenway } 3510 \text { digital ion analyzer instead of } 3310 \text { model. }\end{array}$} \\
\hline
\end{tabular}

\section{Sensors calibration and response time}

Electrochemical performance characteristics of the proposed sensors were systematically evaluated according to IUPAC standards [37].

Table 2 shows the results obtained over a period of one month for two different assemblies of each sensor. Typical calibration plots are shown in Fig. 2 and 3. The sensors displayed constant potential readings within $\pm 2 \mathrm{mV}$ from day to day and the calibration slopes did not change by more than $\pm 2 \mathrm{mV}$ per decade over a period of 42 and 18 days for the coated graphite and platinum wire sensors, respectively.

The required time for the sensors to reach values within $\pm 1 \mathrm{mV}$ of the final equilibrium potential after increasing drug concentration 10 folds was found to be 5 and 7 seconds, for sensors 1 and 2, respectively. The slopes of the calibration plot were 54.8 and $51.6 \mathrm{mV} /$ concentration decade, for the coated graphite and platinum wire sensors, respectively. Deviation from the ideal Nernstian slope $(60 \mathrm{mV})$ stems from the fact that electrode responds to the activity of the drug cation rather than its concentration. 


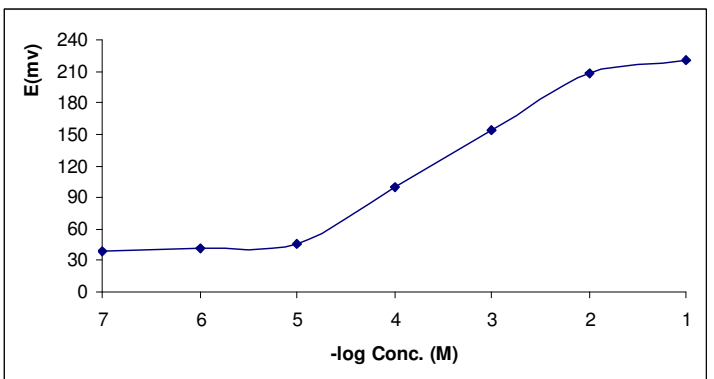

Figure 2. Profile of the potential in $\mathrm{mV}$ versus $-\log$ concentrations of ORP in $\mathrm{M}$ obtained by using sensor 1 .

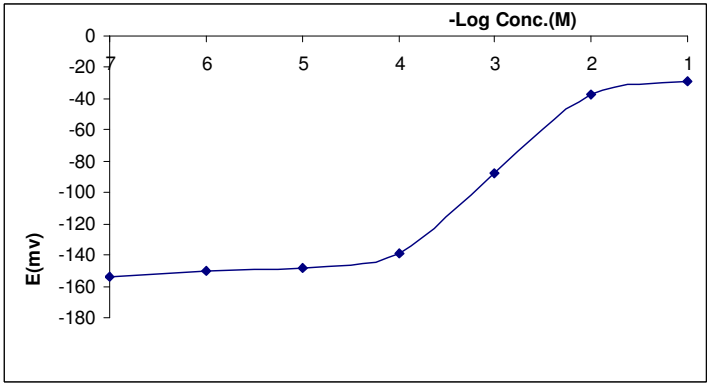

Figure 3. Profile of the potential in $\mathrm{mV}$ versus $-\log$ concentrations of ORP in $\mathrm{M}$ obtained by using sensor 2 .

\section{Sensors $\mathrm{pH}$ and temperature}

In measurements with the two investigated sensors, the experimental parameters were studied to reach the optimum conditions. A pH value within the range 4-7 was found to be optimum from the point of view of both sensor function and the chemical form of the test solution, ORP being in the cationic form in acidic media. Fig. 4 and 5 show the potential $\mathrm{pH}$ profile for $10^{-3}$ and $10^{-4} \mathrm{M}$ drug solutions. Above $\mathrm{pH} \mathrm{8,} \mathrm{the} \mathrm{potentials} \mathrm{displayed} \mathrm{by} \mathrm{the} \mathrm{sensors} \mathrm{sharply} \mathrm{decrease}$ due to formation of non-protonated ORP. Below $\mathrm{pH} 4$, the potentials displayed by the sensors were noisy and unbalanced due to sensor shocking. It was apparent that the sensors responses are fairly constant in BRB solutions of $\mathrm{pH} 4$ 7 , therefore BRB solution of $\mathrm{pH} 6$ was used throughout the measurements.

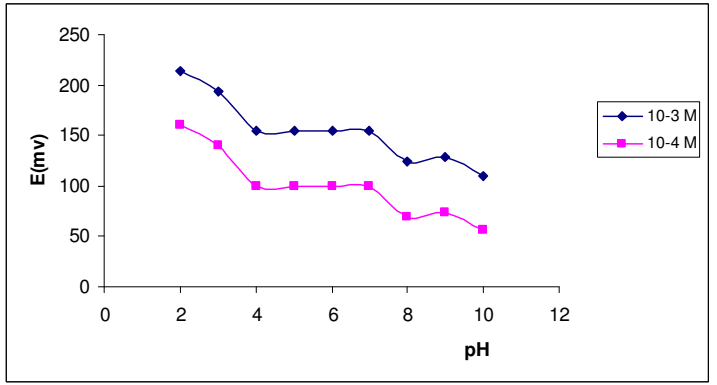

Figure 4. Effect of $\mathrm{pH}$ on the response of sensor 1. 


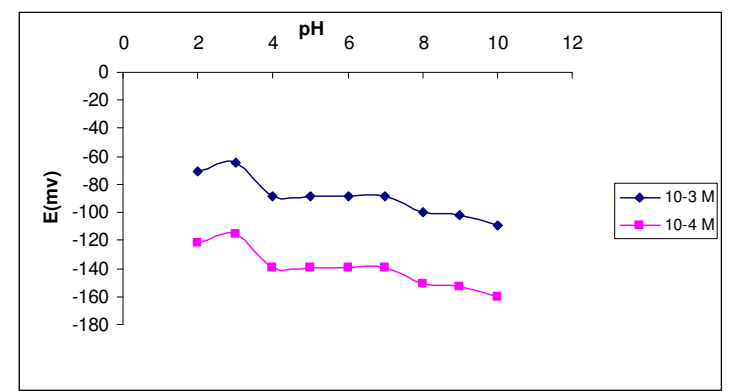

Figure 5. Effect of $\mathrm{pH}$ on the response of sensor 2.

Upon studying the effect of temperature, the suggested sensors exhibited slight gradual increase in their potentials as the temperature increased in the range of 20-35 ${ }^{\circ} \mathrm{C}$. However, the calibration graphs obtained at different temperatures were parallel. The limit of detection, slope and response time did not significantly vary with variation of temperature, indicating reasonable thermal stability of PVC membrane up to $35^{\circ} \mathrm{C}$.

Table 3. Potentiometric selectivity coefficients $\left(\mathrm{K}^{\mathrm{pot}}{ }_{\text {ORP.I }}\right.$ of the two proposed electrodes by using the separate solutions method (SSM) [37].

\begin{tabular}{|c|c|c|}
\hline \multirow{2}{*}{ Interferent $^{\mathrm{b}}$} & \multicolumn{2}{|c|}{ Selectivity coefficient } \\
\cline { 2 - 3 } & ORP-coated graphite & ORP-coated platinum wire $^{\mathrm{a}}$ \\
\hline Degradate $^{\mathrm{c}}$ & $2.1 \times 10^{-3}$ & $5.2 \times 10^{-2}$ \\
\hline Aspirin & $3.2 \times 10^{-2}$ & $3.3 \times 10^{-2}$ \\
\hline Caffeine & $5.6 \times 10^{-2}$ & $6.2 \times 10^{-2}$ \\
\hline Paracetamol & $2.3 \times 10^{-2}$ & $3.1 \times 10^{-3}$ \\
\hline Lactose & $3.0 \times 10^{-3}$ & $5.1 \times 10^{-3}$ \\
\hline Glycine & $5.2 \times 10^{-3}$ & $3.9 \times 10^{-2}$ \\
\hline NaCl & $3.2 \times 10^{-3}$ & $4.2 \times 10^{-2}$ \\
\hline $\mathrm{KCl}$ & $4.6 \times 10^{-3}$ & $3.1 \times 10^{-3}$ \\
\hline CaCl 2 & $3.8 \times 10^{-3}$ & $4.0 \times 10^{-2}$ \\
\hline Propylene Glycol & $6.4 \times 10^{-3}$ & $5.2 \times 10^{-3}$ \\
\hline Mannitol & $3.2 \times 10^{-3}$ & $3.1 \times 10^{-3}$ \\
\hline$\beta$-alanine & $5.3 \times 10^{-3}$ & \\
\hline
\end{tabular}

${ }^{\mathrm{a}}$ Each value is the average of three determinations.

${ }^{\mathrm{b}}$ All interferents are in the form of $1 \times 10^{-3} \mathrm{M}$ solution.

C $o$-methylbenzhydrol.

\section{Sensors selectivity}

The effect of interfering substances upon the performance of the sensors was studied by separate solution method using the following equation [37]:

$-\log \left(\mathrm{K}^{\mathrm{pot}}\right)=\frac{\mathrm{E}_{1}-\mathrm{E}_{2}}{\mathrm{~A} . \mathrm{B}}+\frac{\mathrm{Z}_{\mathrm{A}}}{2.303 \mathrm{RT} / \mathrm{Z}_{\mathrm{A}} \mathrm{F}}+\left(1-\frac{-}{\mathrm{Z}_{\mathrm{B}}}\right) \log a_{\mathrm{A}}$

where $E_{1}$ is the potential measured in $10^{-3} \mathrm{M}$ ORP solution, $E_{2}$ the potential measured in $10^{-3} \mathrm{M}$ interferent solution, $\mathrm{Z}_{\mathrm{A}}$ and $\mathrm{Z}_{\mathrm{B}}$ are the charges of ORP and 
interfering ion, respectively, $\mathrm{a}_{\mathrm{A}}$ is the activity of drug and $2.303 \mathrm{RT} / \mathrm{Z}_{\mathrm{A}} \mathrm{F}$ represents the slope of the investigated sensors ( $\mathrm{mV} /$ concentration decade).

Table 3 shows the potentiometric selectivity coefficients of the proposed sensors in the presence of capsules excipients, degradates, organic and inorganic related substance and also some co-formulated drugs; the results revealed that the proposed membrane sensors displayed high selectivity, and that no significant interference was observed from interfering species. Also, they revealed that sensor 1 displayed greater selectivity for ionic interfering species such as $\mathrm{NaCl}$, $\mathrm{KCl}$, and $\mathrm{CaCl}_{2}$ than did sensor 2 .

Table 4. Determination of ORP in Norflex ${ }^{\circledR}$ tablets by the proposed electrodes and the official method [38].

\begin{tabular}{|c|c|c|c|}
\hline \multirow{2}{*}{$\begin{array}{c}\text { Norflex }{ }^{\circledR} \text { tablets } \\
(10 \mathrm{mg})\end{array}$} & \multicolumn{3}{|c|}{ Recovery $\% \pm$ S.D. ${ }^{a}$ of ORP } \\
\hline & ORP-coated graphite & ORP-coated platinum wire & Official method $^{\mathrm{b}}$ \\
\hline $\begin{array}{c}\text { Batch no. } 3003 \\
\text { t-test } \\
\mathrm{F}^{\mathrm{c}}\end{array}$ & $\begin{array}{c}99.53 \pm 0.88 \\
0.293(2.306) \\
1.18(6.39)\end{array}$ & $\begin{array}{c}100.48 \pm 0.81 \\
2.000(2.306) \\
1.38(6.39)\end{array}$ & $99.36 \pm 0.96$ \\
\hline $\begin{array}{c}\text { Batch no. } 4074 \\
\text { t-test }^{c} \\
\mathrm{~F}^{\mathrm{c}} \\
\text { Mean }\end{array}$ & $\begin{array}{c}100.49 \pm 0.79 \\
1.144(2.306) \\
1.33(6.39) \\
100.01 \pm 0.83\end{array}$ & $\begin{array}{c}99.71 \pm 0.98 \\
0.266(2.306) \\
1.14(6.39) \\
100.09 \pm 0.90\end{array}$ & $99.87 \pm 0.92$ \\
\hline
\end{tabular}

${ }^{\mathrm{a}}$ Average of five determinations.

${ }^{\mathrm{b}}$ HPLC method using methanol-0.05 M ammonium phosphate buffer-acetonitrile (9:8:3 by volume).

${ }^{\mathrm{c}}$ The values in parentheses are the corresponding theoretical values for $\mathrm{t}$ and $\mathrm{F}$ at $\mathrm{P}=0.05$.

Table 4 shows the results obtained for the determination of ORP in pharmaceutical formulations (Norflex ${ }^{\circledR}$ tablets), proving the applicability of the method, as demonstrated by the accurate and precise percentage recovery; the results obtained were also compared with those obtained by using official method [38] (HPLC method using methanol-0.05 M ammonium phosphate bufferacetonitrile (9:8:3 by volume)). No significant difference in results was found. Placebo experiments containing all additives in the same ratio as that used in tablets were investigated. The excipients present in Norflex ${ }^{\circledR}$ tablets (lactose, glucose, mannitol, sodium chloride, magnesium stearate and polyethylene glycol) did not show any interference. Thus, analysis was carried out without prior treatment or extraction.

Table 5. Determination of ORP in spiked human plasma by the proposed sensors.

\begin{tabular}{|c|c|c|}
\hline \multicolumn{3}{|c|}{ Recovery $(\%) \pm$ S.D. $^{a}$} \\
\hline Added, $\mu \mathrm{g} / \mathrm{mL}$ & $\begin{array}{l}\text { ORP-coated } \\
\text { graphite }\end{array}$ & $\begin{array}{l}\text { ORP-coated } \\
\text { platinum wire }\end{array}$ \\
\hline $10^{-3}(461.5)$ & $99.70 \pm 0.39$ & $98.79 \pm 0.72$ \\
\hline $10^{-4}(46.14)$ & $99.40 \pm 0.97$ & $98.32 \pm 0.93$ \\
\hline $10^{-5}(4.615)$ & $98.21 \pm 1.56$ & \\
\hline
\end{tabular}

${ }^{a}$ Average of three determinations. 
Table 5 shows the results obtained for the determination of ORP in spiked human plasma; it was clear from the results that a wide concentration range of the drug could be determined by the investigated sensors as they gave stable results in slopes and $\mathrm{mV}$ readings revealed by the high precision and accuracy of the recovery results. It is also clear from the results shown in Table 5 that sensor 1 is more sensitive than sensor 2 because wider concentration ranges of the drug could be determined.

Fig. 6 shows the reported acid degradation of the drug [13]; the degradation products are $o$-methylbenzhydrol and dimethylethylamine. Table 6 shows the results obtained upon analysis of synthetic mixtures containing different ratios of intact drug to degraded sample, varying from 100:0 to 10:90. The results showed that sensor 1 can be successfully used for selective determination of intact drug in the presence of $>90 \%$ of the degradate. While sensor 2 suffered from great interference when the degradate concentration is up to about $30 \%$. Thus sensor 1 is recommended for use in stability-indicating methods.

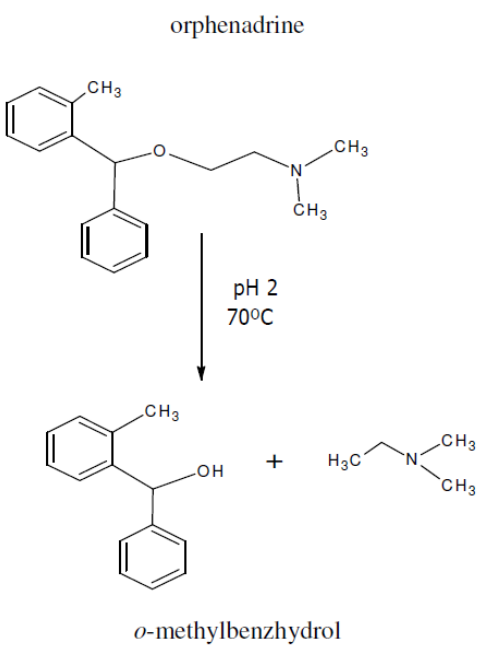

Figure 6. Reported acid degradation of orphenadrine.

Table 6. Determination of ORP in laboratory prepared mixtures containing different ratios of ORP and its induced acid degradation product by the proposed electrodes.

\begin{tabular}{|c|c|c|}
\hline \multirow{2}{*}{$\begin{array}{c}\text { Ratio } \%^{\mathrm{b}} \\
\text { drug: degradate }\end{array}$} & \multicolumn{2}{|c|}{ Drug recovery ${ }^{\mathrm{a}} \% \pm$ S.D. ${ }^{\mathrm{a}}$} \\
\cline { 2 - 3 } & ORP-coated graphite & ORP-coated platinum wire $^{\text {ORP }}$ \\
\hline $100: 0$ & $99.31 \pm 0.49$ & $99.29 \pm 0.37$ \\
\hline $90: 10$ & $99.11 \pm 0.67$ & $99.26 \pm 0.69$ \\
\hline $80: 20$ & $99.49 \pm 0.83$ & $98.79 \pm 0.83$ \\
\hline $70: 30$ & $101.81 \pm 0.73$ & $100.31 \pm 0.79$ \\
\hline $60: 40$ & $102.31 \pm 1.21$ & $109.71 \pm 0.73$ \\
\hline $50: 50$ & $101.53 \pm 0.89$ & $110.39 \pm 0.39$ \\
\hline $40: 60$ & $99.23 \pm 0.63$ & $119.59 \pm 0.63$ \\
\hline $30: 70$ & $99.18 \pm 1.03$ & $145.03 \pm 1.09$ \\
\hline $20: 80$ & $98.73 \pm 0.68$ & $160.13 \pm 0.63$ \\
\hline $10: 90$ & $98.91 \pm 0.83$ & $198.73 \pm 0.83$ \\
\hline
\end{tabular}

${ }^{\mathrm{a}}$ Average of three determinations.

b $1 \times 10^{-3} \mathrm{M}$ in BRB of $\mathrm{pH} 5.5$. 


\section{Conclusion}

The studied electrodes are sufficiently simple and selective for the quantitative determination of ORP in drug bulk powder, pharmaceutical formulations, plasma and in the presence of its degradate. The use of the proposed sensors offers the advantage of fast response, elimination of drug pre-treatment or separation steps and accuracy over wide concentration range. They can therefore be used for the routine analysis of the drug in quality control laboratories.

\section{References}

1. P.P. Gerbino, "Remington, the science and practice of pharmacy", $21^{\text {st }}$ Ed., Lippincott Williams \& Wikins, Baltimore, Maryland, USA (2005) p.1393.

2. S.A. Shama, J. Pharm. Biomed. Anal. 30 (2002) 1385. 10.1016/S07317085(02)00437-5

3. H.M. Saleh, M.M. El-Henawee, G.H. Ragab, S.S. El-Hay, Spectroc. Acta Pt. A-Molec. Biomolec. Spectr. 67 (2007) 1284. 10.1016/j.saa.2006.09.039

4. M.K.S. El-Din, M.A. Abuirjeie, M.H. Abdel-Hay, Anal. Lett. 24 (1991) 2187. 10.1080/00032719108053044

5. R.T. Sane, P.D. Mishra, K.D. Ladage, R.M. Kothurkar, L.S. Joshi, Indian Drugs 26 (1989) 719.

6. A.S. Amin, N.M. El-Kousy, H.A. Dessouki, M. Sultan, Egypt. J. Pharm. Sci. 39 (1998) 463.

7. E.M. Elnemma, F.M. El Zawawy, S.S.M. Hassan, Mikrochim. Acta 110 (1993) 79. 10.1007/BF01243988

8. A. Pelander, I. Ojanpera, J. Sistonen, I. Rasanen, E. Vuori, J. Anal. Toxicol. 27 (2003) 226.

9. A. Valli, A. Polettini, P. Papa, M. Montagna, Ther. Drug Monit. 23 (2001) 287.

10. A.M. Au, R. Ko, F.O. Boo, R. Hsu, G.Z. Perez, Yang, Bull. Environ. Contam. Toxicol. 65 (2000) 112. 10.1007/s001280000102

11. H.N. Al-Kaysi, M.A.S. Salem, Anal. Lett. $20 \quad$ (1987) 1451. 10.1080/00032718708066325

12. S.M. Selkirk, J.H.McB. Miller, G. Smith, A.F. Fell, J. Pharm. Pharmacol. 35 (1983) 23.

13. S.M. Selkirk, A.F. Fell, G. Smith, J.H.M. Miller, J. Chromatogr. 288 (1984) 431. 10.1016/S0021-9673(01)93719-7

14. P. Kissinger, Laboratory Techniques in Electroanalytical Chemistry, Marcel Dekker, New York, 1991 (Chapter 4).

15. D. Diamond, Principles of chemical and biological sensors, in: Chemical Analysis, Vol. 150, Wiley, 1998, Chapter 2, p.19.

16. J.L.F.C. Lima, M.C.B.S.M. Montenegro, Mikrochim. Acta 131 (1999) 187. 10.1007/PL00010030

17. S.S.M. Hassan, R.M. Abdel-Aziz, A.B Abbas, Anal. Chim. Acta 321 (1996) 47. 10.1016/0003-2670(95)00515-3

18. S.S. Hassan, M.M. Amer, S.A. Abdel-Fattah, A.M. El-Kosasy, Talanta 46 (1998) 1395. 10.1016/S0039-9140(98)00008-3 
19. A.M. El-Kosasy, M.A. Shehata, N.Y. Hassan, A.S. Fayed, B.A. El-Zeany, Talanta 66 (2005) 746. 10.1016/j.talanta.2004.12.027

20. A.M. El-Kosasy, J. AOAC Int. 86 (2003) 15.

21. H.T.K. Britton, R.A. Robinson, J. Chem. Soc. (1931) 1456. 10.1039/JR9310001456

22. M. Shamsipur, F. Mizani, M.F. Mousavi, H. Eshghi, H. Karami, Anal. Chim. Acta 589 (2007) 22. 10.1016/j.aca.2007.02.030

23. M. Koudelka-Hep, P.D. Van der Wal, Electrochimica Acta 45 (2000) 2437. 10.1016/S0013-4686(00)00331-5

24. X. Ji, Baokang Jin, J. Ren, J. Jin, T. Nakamura, J. Electroanal. Chem. 579 (2005) 25. 10.1016/j.jelechem.2005.01.020

25. W. Peng, E. Wang, Anal. Chim. Acta 281 (1993) 663. 10.1016/00032670(93)85028-I

26. H. James, G. Carmack, H. Freiser, Anal. Chem. 44 (1972) 856. 10.1021/ac60312a046

27. H. Ibrahim, Y.M. Issa, H.M. Abu-Shawish, J. Pharm. Biomed. Anal. 44 (2007) 8. 10.1016/j.jpba.2007.01.018

28. A. Abbaspour, A. Izadyar, H. Sharghi; Anal. Chim. Acta 525 (2004) 91. 10.1016/j.aca.2004.07.074

29. J.E. Lockridge, N.E. Fortier, G. Schmuckler, J.S. Fritz, Anal. Chim. Acta 192 (1987) 41. 10.1016/S0003-2670(00)85686-X

30. P. Cervini, L.A. Ramos, É.G. Cavalheiro, Talanta 72 (2007) 206. 10.1016/j.talanta.2006.10.017

31. A.A. Bouklouze, A. El Jammal, J.C. Vire, G. J. Patriarche, Anal. Chim. Acta 257 (1992) 41-48. 10.1016/0003-2670(92)80148-Z

32. A.M. EL-Kosasy, M.Y. Salem, M.G. EL-Bardicy, M.K. Abdelrahman, Chem. Pharm. Bull. 56 (2008) 753.

33. J.O'M. Bockris, "Comprehensive Treatise of Electrochemistry", Plenum Press, New York (1981), Section 3.

34. N.A. El-Ragehy, A.M. El-Kosasy, S.S. Abbas, S.Z. El-Khateeb, Anal. Chim. Acta 418 (2000) 93. 10.1016/S0003-2670(00)00941-7

35. A. Graggs, R. Kataky, D. Parker, Analyst 119 (1994) 181. 10.1039/AN9941900181

36. J. Zyka, "Instrumentation in Analytical Chemistry", Ellis Horwood, Chichester, UK, vol.2 1994.

37. IUPAC, Analytical Chemistry Division, Commission on Analytical Nomenclature, Pure Appl. Chem. 72 (2000) 1851-2082.

38. The U.S. Pharmacopoeia, $27^{\text {th }}$ edition, U.S. Pharmacopeial Convention, Rockville, MD, 2004. 